\title{
Therapy resistant neonatal seizures, linear vesicular rash, and unusually early neuroradiological changes: incontinentia pigmenti
}

\author{
A case report, literature review and insight into pathogenesis
}

\author{
Gregor W. Kaczala • Manuela A. Messer • \\ Ken J. Poskitt • Juliette S. Prendiville • Jane Gardiner • \\ Christof Senger
}

Received: 8 June 2007 /Revised: 17 September 2007 / Accepted: 21 September 2007 / Published online: 16 October 2007

(C) Springer-Verlag 2007

\begin{abstract}
Case presentation A substance abusing G2P1 mother spontaneously delivered at term an appropriate for gestational age girl. Neonatal seizures appeared at 21 hours and empiric anticonvulsive and antimicrobial treatment was started. At 25 hours, first vesicles appeared. While routine evaluations remained normal, a head CT revealed multifocal ischemic injuries, and a later MRI showed multifocal petechiae and diffusion abnormalities in the corticospinal tracts. The clinical diagnosis of incontinentia pigmenti (stage 1) was secured by histopathology. Follow-up at 13 months showed global developmental delay.

Discussion We discuss the unusually early bilateral, frontooccipital corticomedullar ischemias (CT day 3). On the MR imaging (day 7) extensive symmetric cerebral corticomedullar destruction and diffusion sequences with corticospinal tracts abnormalities are seen, which then evolve (day 26) to extensive symmetric cerebral destruction. We review the
\end{abstract}

\section{G. W. Kaczala $(\bowtie) \cdot$ M. A. Messer}

Department of Neonatology, Children's and Women's Health

Center of British Columbia,

Vancouver, BC, Canada

e-mail: gregor.kaczala@insel.ch

\section{K. J. Poskitt}

Department of Radiology, Children's and Women's Health Center of British Columbia,

Vancouver, BC, Canada

\section{J. S. Prendiville}

Department of Dermatology, Children's and Women's Health Center of British Columbia,

Vancouver, BC, Canada literature, genetics, suspected pathophysiology and possible neonatal manifestation.

Conclusion Incontinentia pigmenti is rare and, therefore, diagnosis is frequently delayed. Nevertheless, in the setting of therapy refractory seizures, excluded infections, and linear vesicular rash, a high index of suspicion is needed. This is the first report of simultaneous corticomedullar involvement as early as the third day of life.

Keywords Neonatal $\cdot$ Seizure Incontinentia pigmenti (IP) $\mathrm{NEMO} \cdot \mathrm{NF}-\kappa \mathrm{B} \cdot \mathrm{I} \kappa \mathrm{B}$

\section{Introduction}

The neonatal diagnosis of incontinentia pigmenti (IP), despite specific clinical features, is often delayed and made by exclusion once the infectious work-up is negative. As in

\footnotetext{
J. Gardiner

Department of Ophthalmology, Children's and Women's Health

Center of British Columbia,

Vancouver, BC, Canada

C. Senger

Department of Pathology, Children's and Women's Health Center

of British Columbia,

Vancouver, BC, Canada

Present address:

G. W. Kaczala

Department of Neonatology, Frauenklinik, Inselspital,

Effingerstrasse 102,

3012 Bern, Switzerland
} 
the setting of vesicular exanthemas and therapy resistant seizures, neonates are empirically treated for suspected neonatal herpes encephalitis and/or bacterial meningitis. The clinical diagnosis is secured by pathognomonic histological changes in the affected skin.

We would like to draw attention to this frequently (initially) missed diagnosis and describe a girl with clinical and histological features of IP and unusual simultaneous corticomedullar involvement as early as 3 days of life, as previous neuroradiological magnetic resonance imaging (MRI) reports showed either white [20] or grey matter involvement [48].

We review the current literature and discuss the known pathophysiology.

\section{Case presentation}

A gravida 2, para 1 mother using crack, methyl-amphetamine, cocaine, nicotine, and ethanol during pregnancy spontaneously delivered at term an adequate for gestational age girl after 2 hours of ruptured membranes. Family history included a grandmother with a brain aneurysm and a grandfather with apoplexy. TORCH and Group B streptococcus screening were negative. The immediate postnatal period was uneventful. At 21 hours of age, right arm jerking and eye deviation were noted. Intermittently, the infant was pink, having a normal muscular tone with a normal fontanel but weak suck. Phenobarbital, ampicillin, gentamicin and acyclovir were started. The initial hematological and chemical work-up was normal, CSF was xanthochromic but sterile (incl. immunefluorescence testing for HSV). The blood culture grew coagulase negative staphylococcus, which was regarded as a contaminant. A head ultrasound showed a right sided grade I intraventricular hemorrhage with a small germinolytic cyst.

Four hours after the seizure onset, linear vesicles along the lines of Blaschko appeared. Despite therapeutic levels of phenobarbital, apneas, profound desaturations, right sided twitching, tongue protrusion, and eye deviation persisted. The EEG showed an unspecific moderate background suppression, multifocal spikes, and sharp waves arousing from the left hemisphere.

On day 3 of life, a head CT showed bilateral, multifocal ischemic injuries in the occipital and frontal areas (Fig. 1a).

On day 4, a diffuse maculo-papular rash over the trunk and the upper extremities was thought to be a reaction to phenobarbital. As seizures persisted, phenytoin was added. On day 7, an MRI showed multifocal petechiae (Fig. 1b) and abnormal diffusion of the corticospinal tracts (Fig. 1c).

Furthermore, echocardiography, coagulation, congenital infection, and the inborn errors of metabolism screening remained normal. A dermatologist suggested the diagnosis of incontinentia pigmenti (IP), vesico-bullous stage (stage I, Fig. 1e), which was confirmed by skin biopsy (Fig. 1f).

A later MRI (day 26) showed extensive symmetric cerebral destruction involving both gray and white matter (Fig. 1d), corresponding to the areas of restricted diffusion documented on day of life 7 (Fig. 1e). The MR-angiography showed decreased intravascular flow in the middle cerebral arteries but no structural changes. At that point, phenobarbital was a
Fig. 1 a Head CT (without contrast, day 3): frontal and occipital patchy low density changes in the cortex and white matter (white circles). b Head MRI (T2, day 7): general white matter hyperintensity with foci of low signal intensity (black circles). c Head MRI (day 7): diffusion sequences with corticospinal tracts abnormalities (white circles). d Head MRI (T1, day 26): extensive symmetric cerebral destruction of gray and white matter (white circles). e Inside left leg (day 2): linear vesicular exanthema along the lines of Blaschko. f Skin biopsy (H\&E, 200x): IP, vesico-bullous stage with pathognomonic intraepidermal eosinophils $\left(^{*}\right)$ and vesicles $(+)$, covered by the stratum corneum (\#)
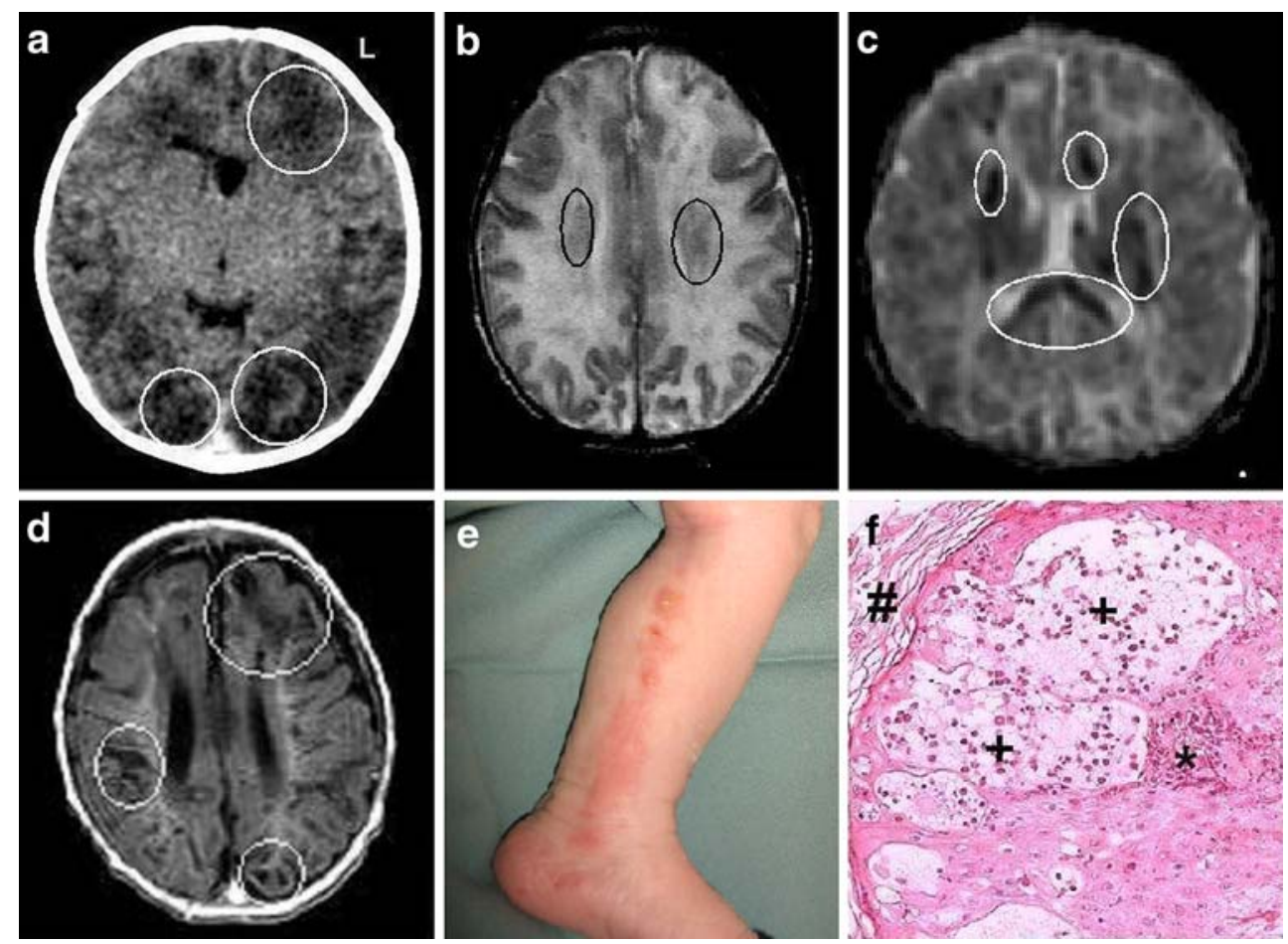
sufficient anticonvulsant therapy. Fundoscopy showed $360^{\circ}$ of peripheral avascularity in both eyes. Bilateral laser coagulation to prevent neovascularization and retinal detachment was performed and repeated at 3 months.

At 13 months of age, she presented with a severe global developmental delay with intermittent seizures. The skin was atrophic along the lines of Blaschko, and she developed recurrent episodes of inflammatory vesicular and verrucous skin lesions, usually associated with febrile illnesses. No more imaging or EEG studies were performed.

\section{Discussion}

We describe a newborn girl with clinical and histological features of IP and with, as yet unreported, early simultaneous corticomedullar involvement. The first report by Garrod in 1906 described the histological melanin deposits in the corium, based on the concept that the corium was 'incontinent' for melanin [12]. Later reports followed in 1925 [3] and 1926 [4]. The reported incidence is around 1:40,000 (M:F ratio 1:37) [6]. IP is X-linked dominant and usually lethal in males [46]. The reported living males were in the setting of Klinefelter Syndrome or gonadal mosaicism [28, 37, 38]. The International Incontinentia Pigmenti Consortium reported that IP is caused by a genomic rearrangement of the gene for the nuclear factor kappa B (NF-kB) essential modulator (NEMO) [42]. The gene is located $200 \mathrm{~kb}$ proximal to the factor VIII locus and is required for the activation of the transcription factor NF- $\mathrm{kB}$ which is central to many immune, inflammatory, and apoptotic pathways [2, 14, 24]. In resting cells, NF- $\mathrm{kB}$ is kept inactive by inhibitory proteins of the I $\kappa \mathrm{B}$ family. NF- $\kappa \mathrm{B}$ activation is induced by the IKB Kinase (IKK) complex and NEMO [23, 25, 51]. After activation by inflammatory stimuli such as tumor necrosis factor (TNF), interleukin-1 (IL-1), or bacterial lipopolisaccharide (LPS), NF-kB is released and accumulated in the nucleus and activates its target genes [19]. NEMO is essential for NF- $\mathrm{kB}$ activation by proinflammatory signals [13]. Therefore, IP is due to genomic rearrangements which make NF-KB activation defective [42].

In the mouse model, it is postulated that autonomous proliferation of NEMO deficient keratinocytes, combined with apoptosis of some NEMO-deficient cells, triggers the expression of proinflammatory mediators by the neighboring wild-type keratinocytes resulting in the development of the cutaneous lesions [32]. Nevertheless, several mechanisms triggering the disease remain unanswered. Nenci at al. suggest that the cutaneous lesions are triggered by the presence of NEMO-deficient cells but that the mosaic presence of NEMO-deficient and wild-type keratinocytes is not needed for disease induction [32]. On the other hand, as apoptosis is a prominent feature in NEMO deficient keratinocytes, their replacement by wild-type cells is thought to explain the cutaneous healing [39]. The pathophysiology of the cerebral lesions is not fully understood [34].

Four clinical stages are defined:

- Stage 1, vesico-bullous (first 2 weeks of life): vesicles and erythema along Blaschko's lines

- Stage 2, verrucous (after several weeks, lasting for weeks): hyperkeratosis, verrucosis on erythematous base. Usually lower limbs. Evolving from stage 1 or unaffected skin

- Stage 3, hyperpigmentation (3-6 months, lasting months to years): asymmetrical, hyperpigmented streaks/whorls along Blaschko's lines

- Stage 4, hypopigmentation (late infancy and adolescence): skin atrophy typically on the flexor side of lower limbs

The most commonly described presenting symptoms in the neonatal period are vesicular rash, exanthema, therapy refractory seizures, paresis [22, 40, 45], and head circumference increase [41]. More unusual features include persistent pulmonary hypertension (PPHN) [16], alopezia $[16,47]$, or in the later neonatal period, low concentrations of IgG subclasses [33].

The differential diagnosis of the vesico-bullous stage includes neonatal infections (herpes simplex, herpes zoster, candidiasis, or syphilis) and various congenital cutaneous conditions (impetigo bullosa, epidermolysis bullosa simplex, transient neonatal pustular melanosis, drug induced rash, hyperkeratosis epidermolytica, and dermatitis herpetiforme) $[6,8,10,18,29]$.

Our neuroradiological findings are unusual, as previous reports from the neonatal period have mentioned:

- Cortical atrophy and ventricular enlargement (CT on day 2) [49]

- Polymicrogyria in the perisylvan area and cortical dysplasia (MRI on day 5) [16]

- Cortical necrosis with subcortical hemorrhage (MRI on day 3) [48]

- Restricted diffusion in the periventricular area (MRI on day 8 ) and filling defects in the middle cerebral artery (MR-angiography on day 13) [21]

- Diffuse hemispheric hemorrhagic necrosis (MRI on day 15) [41]

MRI findings in older children include periventricular leukomalacia [31, 40], cerebellar abnormalities [35], corpus callosum hypoplasia [31], encephalomalacia [9], multiple cerebral infarctions [26], vascular abnormalities [21, 30], unilateral middle cerebral artery occlusion [36], and transient white matter injury [50]. 
However, presence of changes in the neuroradiological imaging does not necessarily mean neurodevelopmental impairment [5]. The pathophysiology of the cerebral and retinal problems have not yet been observed in NEMO $+/-$ mice yet. Therefore, the pathophysiology is not yet understood, and an inflammatory origin is speculated [1].

Our patient was prenatally exposed to cocaine but our radiological findings are not explained by this factor. King et al. reported that neurosonographic structural changes were not more frequent than in healthy controls and were of similar nature [27]. In their cohort, the blood flow in the anterior cerebral artery of cocaine exposed babies increased from day 1 to day 2 and was not explained by a difference in blood pressure. Our observation was a decreased flow in the middle cerebral artery, as had also been seen by others [21]. Other authors reported an association between antenatal cocaine exposure and schizencephaly, interhemispheric cysts [15], pachygyria [17], periventricular leukomalacia [20], cerebral infarction [7], and intraventricular hemorrhage [43].

Our case was diagnosed clinically by the dermatologist and confirmed by histopathology. Therefore, in the presence of a vesicular exanthema following the lines of Blaschko, persisting seizures, and excluded infection, a high index of suspicion is needed. Noteworthy are two previous reports showing coexistence of IP and neonatal HSV infection [11, 44]. Diagnosis is be confirmed by pathognomonic histology.

The prognostic value of imaging is controversial, as one report describes cerebral features of IP in a neurologically normal child [5], whereas in a retrospective cohort, neuroradiological changes are only seen in symptomatic patients [33]. Fundoscopy is mandatory as ocular involvement is frequent; intervention may be necessary and related to neurological involvement. Furthermore, after discharge, periodic ophthalmological and neurological follow-up visits are recommended as well as punctual stomatological controls.

\section{Conclusion}

We present a classical case of IP with unusual neuroradiological findings: early diffusion changes and the evolution of initial cortical and white matter hemorrhage into diffuse necrosis and atrophy. This natural progression most likely explains the global developmental delay observed at 13 months.

The reports in the MRI era describe few neonates with white matter or cortical involvement, with one case of transient white matter injury.
Although neurological symptoms are frequent in IP, the mechanisms of cerebral involvement are not yet fully understood and further research is needed.

\section{References}

1. Aradhya S, Nelson DL (2004) NF-kappaB signaling and human disease. Curr Opin Genet Dev 11:300-306

2. Baldwin Jr AS (1996) The NF-kappa B and I kappa B proteins: new discoveries and insights. Annu Rev Immunol 14:649-683

3. Bardach M (1925) Systematische Naevusbildungen bei einem eineiigen Zwillingspaar. Ein Beitrag zur Naevus Aetilogie. Z Kinderheilkunde 139:452

4. Bloch B (1926) Eigentuemliche bisher nicht beschriebene Pigmentaffektion (incontinentia pigmenti). Schweiz Med Wochenschr 7:404-405

5. Bryant SA, Rutledge SL (2007) Abnormal white matter in a neurologically intact child with incontinentia pigmenti. Pediatr Neurol 36:199-201

6. Carney RG (1976) Incontinentia pigmenti, a world statistical analysis. Arch Dermatol 112:535-542

7. Chasnoff IJ, Bussey ME, Savich R, Stack CM (1986) Perinatal cerebral infarction and maternal cocaine use. J Pediatr 108: 456-459

8. Cohen BA (1987) Incontinentia pigmenti. Neurol Clin 5:361-377

9. Fiorillo L, Sinclair DB, O’Byrne ML, Krol AL (2003) Bilateral cerebrovascular accidents in incontinentia pigmenti. Pediatr Neurol 29:66-68

10. Francis JS, Sybert VP (1997) Incontinentia pigmenti. Semin Cutan Med Surg 16:54-60

11. Fromer ES, Lynch PJ (2001) Neonatal herpes simplex and incontinentia pigmenti. Pediatr Dermatol 18:86-87

12. Garrod AE (1906) Peculiar pigmentation of the skin in an infant. Trans Clin Soc London 39:216

13. Ghosh S, Karin M (2002) Missing pieces in the NF-kappaB puzzle. Cell 109 Suppl:S81-S96

14. Ghosh S, May MJ, Kopp EB (1998) NF-kappa B and Rel proteins: evolutionarily conserved mediators of immune responses. Annu Rev Immunol 16:225-260

15. Gieron-Korthals MA, Helal A, Martinez CR (1994) Expanding spectrum of cocaine induced central nervous system malformations. Brain Dev 16:253-256

16. Godambe S, McNamara P, Rajguru M, Hellmann J (2005) Unusual neonatal presentation of incontinentia pigmenti with persistent pulmonary hypertension of the newborn: a case report. J Perinatol 25:289-292

17. Gomez-Anson B, Ramsey RG (1994) Pachygyria in a neonate with prenatal cocaine exposure: MR features. J Comput Assist Tomogr 18:637-639

18. Gorski JL, Burright EN (1993) The molecular genetics of incontinentia pigmenti. Semin Dermatol 12:255-265

19. Hayden MS, Ghosh S (2004) Signaling to NF-kappaB. Genes Dev 18:2195-2224

20. Heier LA, Carpanzano CR, Mast J, Brill PW, Winchester P, Deck MD (1991) Maternal cocaine abuse: the spectrum of radiologic abnormalities in the neonatal CNS. AJNR Am J Neuroradiol 12:951-956

21. Hennel SJ, Ekert PG, Volpe JJ, Inder TE (2003) Insights into the pathogenesis of cerebral lesions in incontinentia pigmenti. Pediatr Neurol 29:148-150

22. Hubert JN, Callen JP (2002) Incontinentia pigmenti presenting as seizures. Pediatr Dermatol 19:550-552 
23. Israel A (2000) The IKK complex: an integrator of all signals that activate NF-kappaB? Trends Cell Biol 10:129-133

24. Jin DY, Jeang KT (1999) Isolation of full-length cDNA and chromosomal localization of human NF-kappaB modulator $N E M O$ to Xq28. J Biomed Sci 6:115-120

25. Karin M, Ben-Neriah Y (2000) Phosphorylation meets ubiquitination: the control of NF-[kappa]B activity. Annu Rev Immunol 18:621-663

26. Kasai T, Kato Z, Matsui E, Sakai A, Nishida T, Kondo N, Taga T (1997) Cerebral infarction in incontinentia pigmenti: the first report of a case evaluated by single photon emission computed tomography. Acta Paediatr 86:665-667

27. King TA, Perlman JM, Laptook AR, Rollins N, Jackson G, Little B (1995) Neurologic manifestations of in utero cocaine exposure in near-term and term infants. Pediatrics 96:259-264

28. Kirchman TT, Levy ML, Lewis RA, Kanzler MH, Nelson DL, Scheuerle AE (1995) Gonadal mosaicism for incontinentia pigmenti in a healthy male. J Med Genet 32:887-890

29. Landy SJ, Donnai D (1993) Incontinentia pigmenti (BlochSulzberger syndrome). J Med Genet 30:53-59

30. Lee AG, Goldberg MF, Gillard JH, Barker PB, Bryan RN (1995) Intracranial assessment of incontinentia pigmenti using magnetic resonance imaging, angiography, and spectroscopic imaging. Arch Pediatr Adolesc Med 149:573-580

31. Mangano S, Barbagallo A (1993) Incontinentia pigmenti: clinical and neuroradiologic features. Brain Dev 15:362-366

32. Nenci A, Huth M, Funteh A, Schmidt-Supprian M, Bloch W, Metzger D, Chambon P, Rajewsky K, Krieg T, Haase I, Pasparakis M (2006) Skin lesion development in a mouse model of incontinentia pigmenti is triggered by NEMO deficiency in epidermal keratinocytes and requires TNF signaling. Hum Mol Genet 15:531-542

33. Pauly E, Linderkamp O, Poschl J (2005) Incontinentia pigmenti in combination with decreased IgG subclass concentrations in a female newborn. Biol Neonate 88:172-174

34. Pascual-Castroviejo I, Pascual-Pascual SI, Velazquez-Fragua R, Martinez V (2006) Incontinentia pigmenti: clinical and neuroimaging findings in a series of 12 patients. Neurologia 21: 239-248

35. Pascual-Castroviejo I, Roche MC, Martinez Fernandez V, PerezRomero M, Escudero RM, Garcia-Penas JJ, Sanchez M (1994) Incontinentia pigmenti: MR demonstration of brain changes. AJNR Am J Neuroradiol 15:1521-1527

36. Pellegrino RJ, Shah AJ (1994) Vascular occlusion associated with incontinentia pigmenti. Pediatr Neurol 10:73-74

37. Prendiville JS, Gorski JL, Stein CK, Esterly NB (1989) Incontinentia pigmenti in a male infant with Klinefelter syndrome. J Am Acad Dermatol 20:937-940
38. Scheuerle AE (1998) Male cases of incontinentia pigmenti: case report and review. Am J Med Genet 77:201-218

39. Schmidt-Supprian M, Bloch W, Courtois G, Addicks K, Israel A, Rajewsky K, Pasparakis M (2000) NEMO/IKK gamma-deficient mice model incontinentia pigmenti. Mol Cell 5:981-992

40. Shah SN, Gibbs S, Upton CJ, Pickworth FE, Garioch JJ (2003) Incontinentia pigmenti associated with cerebral palsy and cerebral leukomalacia: a case report and literature review. Pediatr Dermatol 20:491-494

41. Shuper A, Bryan RN, Singer HS (1990) Destructive encephalopathy in incontinentia pigmenti: a primary disorder? Pediatr Neurol 6: $137-140$

42. Smahi A, Courtois G, Vabres P, Yamaoka S, Heuertz S, Munnich A, Israel A, Heiss NS, Klauck SM, Kioschis P, Wiemann S, Poustka A, Esposito T, Bardaro T, Gianfrancesco F, Ciccodicola A, D'Urso M, Woffendin H, Jakins T, Donnai D, Stewart H, Kenwrick SJ, Aradhya S, Yamagata T, Levy M, Lewis RA, Nelson DL (2000) Genomic rearrangement in NEMO impairs NFkappaB activation and is a cause of incontinentia pigmenti. The International Incontinentia Pigmenti (IP) Consortium. Nature 405:466-472

43. Spires MC, Gordon EF, Choudhuri M, Maldonado E, Chan R (1989) Intracranial hemorrhage in a neonate following prenatal cocaine exposure. Pediatr Neurol 5:324-326

44. Stitt WZ, Scott GA, Caserta M, Goldsmith LA (1998) Coexistence of incontinentia pigmenti and neonatal herpes simplex virus infection. Pediatr Dermatol 15:112-115

45. Vicente-Villa A, Lamas JV, Pascual AM, Cuesta DL, Marfa MP, Gonzalez-Ensenat MA (2001) Incontinentia pigmenti: a report of ten cases. Eur J Pediatr 160:64-65

46. Wieacker P, Zimmer J, Ropers HH (1985) X inactivation patterns in two syndromes with probable X-linked dominant, male lethal inheritance. Clin Genet 28:238-242

47. Wiklund DA, Weston WL (1980) Incontinentia pigmenti. A fourgeneration study. Arch Dermatol 116:701-703

48. Wolf NI, Kramer N, Harting I, Seitz A, Ebinger F, Poschl J, Rating D (2005) Diffuse cortical necrosis in a neonate with incontinentia pigmenti and an encephalitis-like presentation. Am J Neuroradiol 26:1580-1582

49. Yang JH, Ma SY, Tsai CH (1995) Destructive encephalopathy in incontinentia pigmenti: a case report. J Dermatol 22:340-343

50. Yoshikawa H, Uehara Y, Abe T, Oda Y (2000) Disappearance of a white matter lesion in incontinentia pigmenti. Pediatr Neurol 23:364-367

51. Zandi E, Karin M (1999) Bridging the gap: composition, regulation, and physiological function of the IkappaB kinase complex. Mol Cell Biol 19:4547-4551 